\title{
Dynamic Impacts of Commodity Prices on the Moroccan Economy and Economic, Political and Social Policy Setting
}

\author{
Ahmad Baijou (Corresponding author) \\ School of Business Administration , Al Akhawayn University 53000 Ifrane \\ Ifrane Morocco; Email : A.BAIJOU@AUI.MA \\ Hamza Abdallaoui Maane \\ School of Business Administration, Al Akhawayn University 53000 \\ Ifrane Morocco; Email: H.abdellaoui@aui.ma
}

\section{Doi:10.5901/mjss.2016.v7n2p177}

\begin{abstract}
This research quantifies the dynamic impact of macroeconomic indicators such as, commodity prices, energy prices, subsidy, phosphate prices, import, export, on the Moroccan economy. Cointgration, vector autoregressive (VAR) and vector error correction (VEC) models are used to quantify the effects and causes of macroeconomic indicators on Moroccan economy. The empirical results show that phosphate prices impact, in the short-run, Moroccan merchandise exports and GDP; however, this effect remains insignificant in the long-run. Besides, The results indicate that variation of international energy and grain prices affect merchandise imports. In fact, these prices impact Moroccan imports both in the short-run and the longrun. Conversely, energy and grain prices have no effect on the Consumer Price Index (CPI). Furthermore, unit root and structural breaks analyses of the CPI confirm the resilience of the monetary policy to energy and grain prices shocks. Finally, the outcome of the study indicate that subsidies budget increase with an increasing rate. Hence, subsidies are more affected by factors other than energy and grain prices. Even thought the study is done bout Morocco, the results could be applied to the similar countries in MENA region for economic, political and social policy setting.
\end{abstract}

Keywords: Commodity prices, Unit root, Cointegration, Vector Error Correction Model

\section{Introduction}

The recent surge of commodity prices undermined economic growth prospects and poverty reduction in Morocco. Commodity markets turbulence and the resulting exogenous shocks constitute one of the major challenges facing Moroccan policy makers. High energy and grains prices are a major policy issue, given implications for fiscal policy, business environment, and social stability in an unsteady regional context. The emergence of these conjectural constraints challenges the past political comfort zones and fiscal status quos, and urge the implementation of additional structural reforms.

The literature about economic effects of commodity prices in Morocco mainly focuses about budgetary implications of public subsidies and ignores impacts via other transmission channels. These transmission mechanisms concern merchandise trade, inflation, and economic growth. Nevertheless, subsidies remain a subject with a high social and political importance. They are essentially covering energy and food products in a generalized subventions system considered by several reports ${ }^{1}$ as expensive and inefficient. In 2013, public subsidies represented $6 \%$ of the Gross Domestic Product (GDP), practically the size of the budget deficit.

This paper addresses the general picture of the Moroccan economy in the scope of the unstable commodities markets, and assesses the dynamic economic impact of commodities prices. First, it provides a general outlook on the global commodity markets and the local economy. Then, it addresses relevant transmission mechanisms of commodity prices to the Moroccan economy. Finally, it evaluates, using econometric tools, causality links and the significance of long-run and short-run relations between commodity price and merchandise trade, Consumer Price Index (CPI), Gross Domestic Product (GDP), and public subsidies budget.

\footnotetext{
1 International Monterey Fund (2014): ARTICLE IV CONSULTATION_STAFF REPORTS

La Cour des Comptes (2014): Rapport sur le système de compensation au Maroc, Diagnostic et propositions de réforme.
} 


\section{Research Questions and the Objectives of the Study}

The paramount of this research is to quantify the causes and effects of different macroeconomic indicators among them using Moroccan economy. To identify these causes and effects the empirical analysis models will be developed for the possible relations between commodity prices and Moroccan economic indicators. The previous analysis of the Moroccan economy identified five price transmission channels or mechanisms. These channels represent the possible relations between commodity prices and economic performance, therefore the research questions are as follows

a. Are phosphate price and merchandise exports cointegrated ?.

b. Are phosphate price and GDP cointgrated?.

c. Are energy, grains prices and merchandise imports cointegrated?.

d. Are energy, grain prices and CPI cointegrated ?.

e. Are energy, grain prices and subsidies are cointgrated?.

\section{Literature Review}

To assess the consequences of commodity prices shocks on the U.S. economic cycles, Gubler and Hertweck (2013) constructed a nine-dimensional Structural Vector Autoregressive Model (SVAR). The model is composed from the following variables: commodity price index, inflation rate, Federal Funds rate, employment rate, labor productivity, hours per capita, relative price of investment goods, consumption share in output, and investment share in output. The model showed that commodity price shocks are significant to the macro-ambivalence of the U.S economic cycles, especially to cyclical movements of the Consumer Price Index (CPI). Impulse responses indicate that output, and consumption significantly respond to these shocks. The research also explained that in a response to inflationary threats, the Federal reserve tend to increases interest rates, and consequently cause a decline of consumption and output with a significant negative effect on GDP growth.

Medina (2010) measured the dynamic impact of commodity prices on the fiscal performance of South American countries. The study used Vector Autoregressive (VAR) equations to model commodity prices indexes and budgetary expenditures, revenues, and real GDP. The research concerns eight commodity exporting economies in Latin America, and used quarterly data from 1975 to 2008. The study concludes that Latin American economies are very sensitive to commodity price shocks. According Medina (2010) the economic impact is significant in the eight countries; however, the nature of this impact differs from a country to another. Henceforth, Venezuela seems to be the most sensitive country to commodity price shock in South American. Meanwhile, Chili showed the highest resilience to commodity prices shocks. Chili's reaction to commodity price variance is similar to high income commodity exporting countries such as Canada and Australia. This difference between Chili and other Latin American countries was explained by structural economic factors such as financial transparency, political stability, and fiscal governance.

Cavalcanti and al (2011) examined the impact of the commodity terms of trade level and variance on GDP growth channels namely human capital, physical capital, and total factor productivity. The study developed two models that are ordinary system GMM estimator and an augmented form of conditional pooled mean group CPMG estimator using a sample of 118 countries from 1970 to 2007. The results showed that the commodity terms of trade instability directly operate on physical capital accumulation and reduce economic growth. This effect was observed at a lower degree with human capital acquisition, and essentially investment in human resources. Both causalities are less pronounced in diversified economic structures. The researchers conclude that instructional governance reforms, proper exchange rates management, and economic diversification are the best solutions to smooth the adverse outcomes of the commodity price risks.

International Monetary Fund World Economic Outlook (IMF, 2011) indicates that high commodity prices threaten domestic demand and add economic and social tensions in the commodity importing Middle Income Countries (MIC). In these economies, complications caused by high raw material prices are tremendously significant for two reasons. First, food ratio in the Consumption Price Index (CPI) basket is higher is these countries than in industrial countries. Hence, they are more disposed to experience long term inflationary pressures due to high commodity prices. Second, the high share of commodities in exports and imports directly expose current balances and foreign exchange reserves to international markets shocks. Nonetheless, the significance of these factors varies according the country's integration into global markets, the resilience of the monetary policy, and the level of local harvests subject to weather conditions. For Low Income Countries (LIC), the IMF published a "vulnerability exercise" that simulates scenarios of commodity price shock (Fabrizio, 2012). The major challenge facing LIC is to build macroeconomic buffers through tight budgetary policy, efficient public investments, and a diversified economy. In case of a commodity price shock, LICs should have fiscal 
flexibility and leverage to preserve revenues and guarantee sufficient investment levels. The LICs must also build efficient social safety nets, and adopt appropriate monetary policies to prevent inflationary spirals.

\section{Methodological Approach}

Appropriate econometric models that explore and investigate the properties of economic time series that were integrated processes, such as the previous relations between commodity prices, which contained a unit root in their dynamics are cointegration in systems of equations as shown by Hendry and Juselius (2000) that when data were non-stationary purely due to unit roots, they could be brought back to stationarity by the linear transformation of differencing. Besides, Granger causality testing of Vector Autoregressive (VAR) models and long-run and short-run equilibrium relations using Vector Error Correction Models (VECM) are used.

\subsection{Stationarity Tests}

Unit root testing and the determination of integration orders of the studied time series at level and after log transformation and first differentiation. The stationarity tests will concerns, Moroccan economic indicators GDP, CPI, and subsidies in one side, and commodity prices phosphate, energy, and grains in an other side.

In case the stochastic process $x_{t}$ has a unit root, it is said that $x_{t}$ is a not stationary. The process $x_{t}$ is said to be stationary if:

- The expected value of $x_{t}$ does not depend on $\mathrm{t}$.

- The variance of $x_{t}$ is constant and independent of $\mathrm{t}$.

- The covariance of $x_{t}$ and $x_{t-1}$ is constant and independent of $\mathrm{t}$

To model a non-stationary process, the process should be de-trended. A non-stationary process can be de-trended and transformed into a stationary process by:

- Log transformation.

- Differentiation, where $d\left(x_{t}\right)=x_{t}-x_{t-1}$

This paper uses three unit roots tests to determine the integration order and the stationarity of the studied time series. The three unit root tests are: the augmented form of the Dikey and Fuller test (1979) (ADF), the KPSS test and the Zivot and Andrews test.

The augmented Dikey-Fuler procedure examines weak stationarity by inspecting the existence of a unit root. This test determines if the stochastic process' mean and variance are contingent on the time t. The augmented form of the test contains dependent variable's lags in order to obtain white noise residuals, and avoid the error term's serial correlation. The length of the lag term will be determined using the Schwarz Info Criterion (SC). The augmented Dickey Fuller test proposes three Ordinary Least Square (OLS) equations:

$$
\begin{aligned}
& \Delta y_{t}=\gamma y_{t-1}+\sum_{i=1}^{p} \beta_{i} \Delta y_{t-i}+u_{t} \\
& \Delta y_{t}=\alpha_{0}+\gamma y_{t-1}+\sum_{i=1}^{p} \beta_{i} \Delta y_{t-i}+u_{t} \\
& \Delta y_{t}=\alpha_{0}+\gamma y_{t-1}+\alpha_{2} t+\sum_{i=1}^{p} \beta_{i} \Delta y_{t-i}+u_{t}
\end{aligned}
$$

Where the error term $u_{t}$ of the three equation is independent and identically distributed (iid). The null hypothesis of the ADF test is the presence of a unit root, and the decision is based on MacKinnon (1991) critical values (table 3). One of the major weaknesses of the Augmented Dickey Fuller procedure is the determination the exact order of integration of an I (0) process when this process is close to be I(1). Therefore, this paper uses two additional stationarity tests.

The second unit root test is the Kwiatkowski-Phillips-Schmidt-Shin (KPSS) test (1992). The KPSS is Lagrange Multiplier (LM) test that includes also constant and constant-trend components. It is a one tail (right side) tests for the random walk's variance zero equality where the null hypothesis assumes stationarity. The asymptotic critical values of the KPSS test are presented in (table 5).

The third unit root test is the Zivot and Andrews test (1992). The ADF test does not consider the existence of structural breaks. In case of a structural break, traditional unit root tests loose power. The Zivot-Andrews test accepts a single structural variation in the time series. The test is based on the Perron (1989) unit root test, and considers the existence of the break in the intercept, the trend, or both the intercept and the trend. The Zivot-Andrews methodology proposes three Ordinary Least Square (OLS) models:

$$
\begin{aligned}
& \Delta y_{t}=\alpha_{0}+\gamma y_{t-1}+\alpha_{2} t+\theta_{1} D U_{t}+\sum_{i=1}^{p} \beta_{i} \Delta y_{t-i}+u_{t} \\
& \Delta y_{t}=\alpha_{0}+\gamma y_{t-1}+\alpha_{2} t+\theta_{2} D T_{t}+\sum_{i=1}^{p} \beta_{i} \Delta y_{t-i}+u_{t} \\
& \Delta y_{t}=\alpha_{0}+\gamma y_{t-1}+\alpha_{2} t+\theta_{1} D U_{t}+\theta_{2} D T_{t}+\sum_{i=1}^{p} \beta_{i} \Delta y_{t-i}+u_{t}
\end{aligned}
$$


Where DU and DT are two dummy variables function of the breakpoint (B):

$$
\begin{aligned}
D U_{t} & = \begin{cases}1, & t>B \\
0, & \text { otherwise }\end{cases} \\
D T_{t} & =\left\{\begin{aligned}
t-T B, & t>B \\
0, & \text { otherwise }
\end{aligned}\right.
\end{aligned}
$$

The null hypothesis of this test assumes unit root, and the rejection decision is based on the asymptotic critical values in (table 7). Tests like Lumsdaine and Papell (1997) test can accept more than one structural break. Nevertheless, the scope of the paper and the nature of the time series used do not require it.

\subsection{Granger causality tests}

Granger causality testing of integrated time series. The causality analysis is Performed based on VAR modeling of stationary time series.

Granger causality using Vector Autoregressive VAR (p) model is useful to determine time causality among two or more variables. Granger causality approach does not determine direct causality, but concludes if predicting the values of a time series is better done with the past values of another time series. A VAR (p) model of stationary_processes $y_{1 t}$ and $y_{2 t}$ is defined:

$$
\begin{aligned}
& y_{1 t}=\gamma_{1}+\sum_{1}^{p} a_{1 P} y_{1 t-P}+\sum_{1}^{p} \beta_{1 P} y_{2 t-P}+v_{1 t} \\
& y_{2 t}=\gamma_{2}+\sum_{1}^{p} a_{2 P} y_{1 t-P}+\sum_{1}^{p} \beta_{2 P} y_{2 t-P}+v_{2 t}
\end{aligned}
$$

Where $v_{1 t}$ and $v_{1 t}$ are independent and identically distributed (iid) error terms. Pairwise granger causality test considers that:

- $y_{1 t}$ does not cause $y_{2 t}$ if: $\boldsymbol{a}_{11}=\boldsymbol{a}_{12}=\boldsymbol{a}_{13}=\cdots=\boldsymbol{a}_{1 P}=0$

- $y_{2 t}$ does not cause $y_{1 t}$ if: $\boldsymbol{\beta}_{\mathbf{1 1}}=\boldsymbol{\beta}_{\mathbf{1 2}}=\boldsymbol{\beta}_{13}=\cdots=\boldsymbol{\beta}_{1 P}=0$

Using an F-test, the granger method checks the two following hypotheses:

$\left\{\begin{array}{c}H_{0}: a_{11}=a_{12}=a_{13}=\cdots=a_{1 P}=0 \\ H_{1}: \text { at least one coeficient } a_{1 P} \text { is } \neq 0\end{array}\right.$
$\left\{\begin{array}{c}H_{0}: \beta_{11}=\beta_{12}=\beta_{13}=\cdots=\beta_{1 P}=0 \\ H_{1}: \text { at least one coeficient } \beta_{1 P} \text { is } \neq 0\end{array}\right.$

The order $p$ designates the number of lags used in the VAR models (3.7) and (3.8). In this paper, the order $p$ is selected based on Schwarz Info Criterion (SC).Moreover, the usage of the vector form of the Autoregressive models allows testing for pairwise granger causality of more than two time series.

\subsection{Cointegration analysis}

Examination of the long run relations of non-level stationary time series. Then determining the number of cointegrating vectors for each relation using Johansen cointegration tests.

First presented by Granger (1981), cointegration is a central concept in the modern econometrics. The regression of non-stationary stochastic processes lead to spurious regressions unless they are cointegrated. The cointegration principle is based on the long-run equilibrium principle between stochastic processes. Hence, a non-stationary processes, but integrated at the same order, have a long run relationship if there exists a stationary linear combination of these processes. In other words, two time series $x_{t}$ and $y_{t}$, both $I(1)$, are cointegrated of order $(1,1)$ if there exist a linear combination if $x_{t}$ and $y_{t}$ that is I (0). In this case, one can say that $x_{t}$ and $y_{t}$ have one cointegrating vector or one a long-run relationship:

$x_{t} \rightarrow I(1)$ and $y_{t} \rightarrow I(1)$

The Ordinary Least Square equation:

$y_{t}=a x_{t}+b+\varepsilon_{t}(3.9)$

could be written in the form: $\boldsymbol{\varepsilon}_{\boldsymbol{t}}=\boldsymbol{y}_{\boldsymbol{t}}-\boldsymbol{a} \boldsymbol{x}_{\boldsymbol{t}}-\boldsymbol{b}$. If the error term $\boldsymbol{\varepsilon}_{\boldsymbol{t}}$ is stationary $\boldsymbol{\varepsilon}_{\boldsymbol{t}} \rightarrow \boldsymbol{I}(\mathbf{0})$, then $x_{t}$ and $y_{t}$ are cointegrated: $\boldsymbol{x}_{t}, \boldsymbol{y}_{t} \sim \boldsymbol{C I}(\mathbf{1}, \mathbf{1})$.

In general, for $n$ number of time series there might exist up to $n-1$ cointegrating vectors. Engle and Granger (1987) define the general form of cointegration as follow:

If $Y_{t}$ denotes an $n \times 1$ vector of $I(d)$ processes, and there exist a $n \times 1$ vector $\beta$ such that $\boldsymbol{Y}_{\boldsymbol{t}}^{\prime} \boldsymbol{\beta} \sim \boldsymbol{I}(\boldsymbol{d}-\boldsymbol{b})$ where $\boldsymbol{d} \geq \boldsymbol{b} \geq \mathbf{0}$ then $\boldsymbol{Y}_{\boldsymbol{t}} \sim \boldsymbol{C I}(\boldsymbol{d}, \boldsymbol{b})$.

In case of cointegration, the equation (3.9) represents the long term relationship. Where the short term dynamics could be represented in a dynamic linear regression called the Autoregressive Distributed lag (ADL) model:

$$
y_{t}=a_{0}+a_{1} y_{t-1}+a_{2} x_{t}+a_{3} x_{t-1}+v_{t}(3.10 \mathrm{a})
$$


Where $\boldsymbol{v}_{\boldsymbol{t}}$ is an independent and identically distributed (iid) error term. Equation (3.10 a) could be rewritten as:

$\Delta y_{t}=a_{0}+\left(a_{1}-1\right) y_{t-1}+a_{2} \Delta x_{t}+\left(a_{2}+a_{3}\right) x_{t-1}+v_{t}(3.10 b)$

Engle and Granger (1987) approach to cointegration considers that the equation (3.10 b) could include long term dynamics in equation (3.9) and be rewritten as a single equation form of the Error Correction Model (ECM) :

$\Delta y_{t}=\gamma \Delta x_{t}+\delta\left(y_{t-1}-a x_{t-1}-b\right)+v_{t}$ With $\delta<0$ (3.11)

According to Johansen $(1988,1991)$ a Vector Autoregressive (VAR) equation of order $p$ defined in equations (3.7) and (3.8) has matrix representation:

$Y_{t}=A_{1} Y_{t-1}+A_{2} Y_{t-2}+\cdots+A_{p} Y_{t-p}+u_{t}$

where $Y_{t}$ denotes an $n \times 1$ vector of cointegrated I(1) processes, could be written as Vector Error Correction Model (VECM) matrix form:

$\Delta Y_{t}=\Pi Y_{t-1}+\sum_{i=1}^{p-1} \Gamma_{i} \Delta Y_{t}+u_{t} \quad(3.13 \mathrm{a})$

where $\Gamma_{i}=-\sum_{k=i+1}^{p} A_{k}, \Pi=\sum_{i=1}^{p} A_{i}-I$, and the Gaussian error $\boldsymbol{u}_{t} \sim \boldsymbol{N}(\mathbf{0}, \Omega)$

The matrix $\Pi$ with a reduced rank $r$, encompasses the long-run associations, and can be decomposed such as $\boldsymbol{\Pi}=\boldsymbol{\alpha} \boldsymbol{\beta}^{\prime}$. The reduced rank $r$ represents the number of cointegrating vectors. Hence, equation 3.13 could be rewritten as :

$\Delta Y_{t}=\alpha \beta^{\prime} Y_{t-1}+\sum_{i=1}^{p-1} \Gamma_{i} \Delta Y_{t}+u_{t}(3.13$ b)

The VECM's (3.13) coefficients model the following:

- The matrix $\boldsymbol{\alpha}$ represents the adjustment to equilibrium speed.

- The matrix $\boldsymbol{\beta}^{\prime}$ represents long-run equilibrium relationship coefficients.

- The matrix $\boldsymbol{\Gamma}_{i}$ represents short-run variations due to variables changes.

To examine cointerating relationships between the processes $\boldsymbol{Y}_{\boldsymbol{t}}$, Johansen (1991) suggest a procedure based of the eigenvalues of the matrix $\Pi$. This test determines the rank of the matrix $\Pi$ based on the number of eigenvalues significantly different from 0 . To determine the cointegration order, Johansen (1991) proposes two log- likelihood ratio tests: the trace (3.14) and the maximum eigenvalue (3.15) tests.

$$
\begin{aligned}
& \lambda_{\text {trace }}=-T \sum_{t=r+1}^{n} \ln \left(1-\hat{\lambda}_{i}\right) \\
& \lambda_{\text {max eigenvalue }}=-T \ln \left(1-\hat{\lambda}_{r+1}\right)(3.15)
\end{aligned}
$$

Where $\mathrm{T}$ is the sample size. The null hypothesis of the trace tests assumes less than $r$ cointegrating vectors, and an undetermined alternative. While, the maximum eigenvalue test's null hypothesis assumes $r$ cointegrating vectors, and an alternative of $r+1$ vectors. The $\lambda_{\text {trace }}$ and $\lambda_{\max }$ asymptotic critical values are given by Johansen and Juselius (1990).

\subsection{Vector Error Correction Modeling}

In case of cointegrating relations, develop Vector Error Correction Models (VECM) of using Johansen methodology, and perform Wald test statistics for short-run equilibrium relations. The unit root tests (ADF, KPSS, and Zivot Andrews) show that two or more time series are integrated at the same order, and Johansen tests indicate that they are cointegrated, then these time series could be modeled as an Vector Error Correction Model (VECM). Represented in the matrix form in equation (3.12), the VECM regression equations of two I(1) and cointegrated time series $\boldsymbol{x}_{\boldsymbol{t}}$ and $\boldsymbol{y}_{\boldsymbol{t}}$ could be written as:

$$
\begin{aligned}
& \Delta y_{t}=c_{1}+\delta_{1}\left(y_{t-1}-a x_{t-1}-b\right)+\sum_{1}^{p} \beta_{1 p} \Delta y_{t-P}+\sum_{1}^{p} \gamma_{1 p} \Delta x_{t-P} \text { (3.16) } \delta_{1}<0 \\
& \Delta x_{t}=c_{2}+\delta_{2}\left(y_{t-1}-a x_{t-1}-b\right)+\sum_{1}^{p} \beta_{2 p} \Delta y_{t-P}+\sum_{1}^{p} \gamma_{2 P} \Delta x_{t-P} \text { (3.17) } \delta_{2}<0
\end{aligned}
$$

Granger causality tests for causal relations between two time series; meanwhile, VECM allows testing for both short-run and long-run causality. The VECM equation could model more than two time series, where the number of cointegrating vectors is determined using Johansen cointegration max-eigenvalue and trace tests.

\subsection{Long-run and short run causality using VECM}

Granger causality method using VAR ( $p$ ) models do not test for direct or instantaneous causality between variable. After the development of the VECM, presented in the matrix form (3.12) and equations form in (3.16) and (3.17), causality 